\title{
TU/e EmonONEN

\section{Behaviour of a tall vertical gas-evolving cell. Part I: Distribution of void fraction and of ohmic resistance}

\section{Citation for published version (APA):}

Janssen, L. J. J., \& Visser, G. J. (1991). Behaviour of a tall vertical gas-evolving cell. Part I: Distribution of void fraction and of ohmic resistance. Journal of Applied Electrochemistry, 21(5), 386-394.

https://doi.org/10.1007/BF01024573

DOI:

10.1007/BF01024573

Document status and date:

Published: 01/01/1991

\section{Document Version:}

Publisher's PDF, also known as Version of Record (includes final page, issue and volume numbers)

\section{Please check the document version of this publication:}

- A submitted manuscript is the version of the article upon submission and before peer-review. There can be important differences between the submitted version and the official published version of record. People interested in the research are advised to contact the author for the final version of the publication, or visit the $\mathrm{DOI}$ to the publisher's website.

- The final author version and the galley proof are versions of the publication after peer review.

- The final published version features the final layout of the paper including the volume, issue and page numbers.

Link to publication

\section{General rights}

Copyright and moral rights for the publications made accessible in the public portal are retained by the authors and/or other copyright owners and it is a condition of accessing publications that users recognise and abide by the legal requirements associated with these rights.

- Users may download and print one copy of any publication from the public portal for the purpose of private study or research.

- You may not further distribute the material or use it for any profit-making activity or commercial gain

- You may freely distribute the URL identifying the publication in the public portal.

If the publication is distributed under the terms of Article 25fa of the Dutch Copyright Act, indicated by the "Taverne" license above, please follow below link for the End User Agreement:

www.tue.nl/taverne

Take down policy

If you believe that this document breaches copyright please contact us at:

openaccess@tue.nl

providing details and we will investigate your claim. 


\title{
Behaviour of a tall vertical gas-evolving cell. Part I: Distribution of void fraction and of ohmic resistance
}

\author{
L. J. J. JANSSEN*, G. J. VISSER ${ }^{\ddagger}$ \\ Faculty of Chemical Technology* and Computing Centre ${ }^{\ddagger}$, Eindhoven University of Technology, PO Box 513, \\ $5600 \mathrm{MB}$ Eindhoven, The Netherlands
}

Received 30 April 1990; revised 18 August 1990

Electrolysis of a $22 \mathrm{wt} \% \mathrm{NaOH}$ solution has been carried out in a vertical tall rectangular cell with two segmented electrodes. The ohmic resistance of the solution between a segment pair has been determined as a function of a number of parameters, such as, current density and volumetric rate of liquid flow. It has been found that the ohmic resistance of the solution during the electrolysis increases almost linearly with increasing height in the cell. Moreover, a relation has been presented describing the voidage in the solution as a function of the distance from the electrodes and the height in the cell.

\section{Notation}

$A_{\mathrm{e}} \quad$ electrode surface area $\left(\mathrm{m}^{2}\right)$

$a_{\mathrm{s}} \quad$ parameter in Equation $12\left(\mathrm{~A}^{-1}\right)$

$b_{\mathrm{s}} \quad$ parameter in Equation 12

$d \quad$ distance $(\mathrm{m})$

$d_{\mathrm{ac}} \quad$ distance between the anode and the cathode $(\mathrm{m})$

$d_{\mathrm{wm}} \quad$ distance between the working electrode and an imaginary separator $(\mathrm{m})$

$F \quad$ Faraday constant $\left(\mathrm{C} \mathrm{mol}^{-1}\right)$

$h \quad$ height from the leading edge of the working electrode corresponding to height in the cell $(\mathrm{m})$

$h_{\mathrm{e}} \quad$ distance from the bottom to the top of the working electrode $(\mathrm{m})$

$h_{\mathrm{s}} \quad$ height of a segment of working electrode $(\mathrm{m})$

I current (A)

$I_{20} \quad$ current for segment pair 20 (A)

$I_{1-19}$ total current for the segment pairs from 1 to 19 inclusive (A)

$I_{x-19} \quad$ total current for the segment pairs from $x$ to 19 inclusive (A)

$i \quad$ current density $\mathrm{A} \mathrm{m}^{-2}$

$N_{\mathrm{s}} \quad$ total number of gas-evolving pairs

$n_{1} \quad$ constant parameter in Equation 8

$n_{\mathrm{a}} \quad$ number of electrons involved in the anodic reaction

$n_{\mathrm{c}} \quad$ number of electrons involved in the cathodic reaction

$n_{\mathrm{s}} \quad$ number of a pair of segments of the segmented electrodes from their leading edges

$Q_{\mathrm{g}} \quad$ volumetric rate of gas saturated with water vapour $\left(\mathrm{m}^{3} \mathrm{~s}^{-1}\right)$

$Q_{1} \quad$ volumetric rate of liquid $\left(\mathrm{m}^{3} \mathrm{~s}^{-1}\right)$

$R \quad$ resistance of solution $(\Omega)$

$R_{20} \quad$ resistance of solution between the top segments of the working and the counter electrode $(\Omega)$

$R_{\mathrm{p}} \quad$ resistance of bubble-free solution $(\Omega)$

$R_{\mathrm{p}, 20} \quad R_{\mathrm{p}}$ for segment pair $20(\Omega)$

$r_{\mathrm{s}} \quad$ reduced specific surface resistivity

$r_{\mathrm{s}, 0} \quad r_{\mathrm{s}}$ at $h=0$

$r_{\mathrm{s}, 20} \quad r_{\mathrm{s}}$ for segment pair 20

$r_{\mathrm{s}, \infty} \quad r_{\mathrm{s}}$ for uniform distribution of bubbles between both the segments of a pair

$r_{\mathrm{s}, \infty, 20} \quad r_{\mathrm{s}, \infty}$ for segment pair 20

$S_{\mathrm{b}} \quad$ bubble-slip ratio

$S_{\mathrm{b}, 20} \quad S_{\mathrm{b}}$ at segment pair 20

$S_{\mathrm{b}, h} \quad S_{\mathrm{b}}$ at height $h$ in the cell

$T$ temperature (K)

$V_{\mathrm{m}} \quad$ volume of $1 \mathrm{~mol}$ gas saturated with water vapor $\left(\mathrm{m}^{3} \mathrm{~mol}^{-1}\right)$

$v_{1} \quad$ linear velocity of liquid $\left(\mathrm{m} \mathrm{s}^{-1}\right)$

$v_{1,0} \quad v_{1}$ through interelectrode gap at the leading edges of both electrodes $\left(\mathrm{m} \mathrm{s}^{-1}\right)$

$w_{\mathrm{e}} \quad$ width of electrode (m)

$x \quad$ distance from the electrode surface $(\mathrm{m})$

$Z \quad$ impedance $(\Omega)$

$Z^{\prime} \quad$ real part of impedance $(\Omega)$

$Z^{\prime \prime} \quad$ imaginary part of impedance $(\Omega)$

$\rho \quad$ resistivity of solution $(\Omega \mathrm{m})$

$\rho_{\mathrm{p}} \quad$ resistivity of bubble-free solution $(\Omega \mathrm{m})$

$\beta \quad$ gas volumetric flow ratio

$\beta_{20} \quad \beta$ at segment pair 20

$\gamma_{\mathrm{s}} \quad$ specific surface resistivity $\left(\Omega \mathrm{m}^{2}\right)$

$\gamma_{s, p} \quad \gamma_{s}$ for bubble-free solution $\left(\Omega \mathrm{m}^{2}\right)$

$\delta \quad$ thickness of Nernst bubble layer (m)

$\delta_{0} \quad \delta$ at $h=0(\mathrm{~m})$

$\varepsilon \quad$ voidage

$\varepsilon_{x, 0} \quad \varepsilon$ at $x$ and $h=0$

$\varepsilon_{0,0} \quad$ voidage at the leading edge of electrode where $x=0$ and $h=0$

$\varepsilon_{\infty, h} \quad$ voidage in bulk of solution at height $h$

$\varepsilon_{\infty, 20} \quad$ voidage in bubble of solution at the leading edge of segment pair 20 


\section{Introduction}

Vertical electrolyzers with narrow inter-electrode gaps are used to produce gases such as chlorine, hydrogen and oxygen. Gas bubbles formed at one or both electrodes are present in the solution between the anode and the cathode. These non-conductive bubbles cause an increase in ohmic resistance and in ohmic potential drop over the solution. Moreover, bubbles attached to the electrode surface reduce the surface area of the electrode available for the electrode reaction and cause a rise in the local current density and of the overvoltage. It is well known that the bubble effect is significant at high-current densities in a narrow interelectrode gap. Insight into the distribution of void fraction and of current in the cell is of great interest in optimising the design of gas-evolving electrolysis cells.

Recently, Vogt [1] published an extensive review on current distribution in a vertical gas-evolving cell. To calculate the current distribution, knowledge of the voidage distribution over the sectional area of the inter-electrode gap and that in the vertical direction is necessary. Practically all theoretical calculations for the current distribution are based on the assumption of a uniform distribution of bubbles at each sectional area perpendicular to the flow direction of solution and bubbles. Vogt [2] and Sillen [3] introduced the concept of a bubble layer adjacent to the gas-evolving electrode, its thickness is equal to the average bubble diameter [3] or to the diameter of the largest attached bubble [2].

Bongenaar-Schlenter $[4,5]$ determined the degree of screening in the solution by bubbles as a function of the distance from a hydrogen-evolving electrode in a $6 \mathrm{~mm}$ gap between this electrode and a membrane. These experiments show that the bubble layer has a thickness, $\delta$, being a factor of about 10 larger than the average bubble diameter. To calculate the ohmic resistance of the solution in the gap between the gas evolving electrode and the membrane a two-layer model was used $[4,5]$. The effect of the void fraction in the bulk solution on the void fraction at the surface of the gas-evolving electrode was not taken into account $[4,5]$ and is completely unknown. Moreover, no results have been published about the thickness of the bubble layer at large void fractions of the bulk solution in a tall vertical cell with a very narrow inter-electrode gap.

Various models are proposed to describe the effect of the gas voidage in the bulk of solution on the gas voidage in the bubble layer adjacent to the electrode surface. The ohmic resistance of the solution is affected by the distribution of the gas voidage in the solution. To verify these models, ohmic-resistance experiments have been carried out.

\section{Experimental details}

\subsection{Electrolysis cell and electrodes}

The parallel-plate electrochemical cell and the flow circuit have been described in [6]. The solution is pumped from a solution reservoir overflow-vessel upwards through the inter-electrode gap. Both electrodes were made from $1 \mathrm{~mm}$ thick nickel plate and were divided into 20 segments, each $0.010 \mathrm{~m}$ in width and $0.024 \mathrm{~m}$ in height, with a perspex-filled length of $1 \mathrm{~mm}$ between successive segments. The distance between the electrodes was $3.2 \mathrm{~mm}$. This distance was adjusted by placing a $3 \mathrm{~mm}$ thick perspex frame with a hole of $0.010 \mathrm{~m}$ in width and of $0.80 \mathrm{~m}$ in length by sealing this frame with two Teflon sheets of $0.1 \mathrm{~mm}$ thickness. The cross-sectional area of the flow channel between the electrodes was $32 \mathrm{~mm}^{2}$.

\subsection{Electrical measurements}

Current distribution. The potential difference between each pair of electrode segments was adjusted by a special constant-voltage source with 20 independent channels. Each segment was connected to the constantvoltage source by two contacts, one for the power supply and the other for the control of the potential. The potential range of the constant-voltage source was 0 to $50 \mathrm{~V}$ and the maximum current load for a pair of segments was $2.5 \mathrm{~A}$.

The impedance measurements were carried out with a Solartron 1250 Frequency Responce Analyser and a Solartron Electrochemical Interface 1286, coupled with a HP microcomputer. The interface was used in the galvanostatic mode, where a controlled direct circuit was driven through an electrode-segment pair. The impedance of the part of the cell with this segment pair, was determined in the frequency range from about 3000 to $6000 \mathrm{~Hz}$, unless otherwise stated. In this frequency range the imaginary part of impedance was zero. Usually, the impedance was determined for the top pair of electrode segments.

\subsection{Void fraction}

To determine the void fraction in the solution leaving the top of the cell, a glass valve with a curve inner tube of $7.72 \times 10^{-6} \mathrm{~m}^{3}$ in volume was placed between the outlet of the cell and the solution reservoir. The length of the connection tube between the valve and the outlet of the cell was about $0.20 \mathrm{~m}$ and its inner diameter was $15 \mathrm{~mm}$.

To measure the void fraction, the solution flow was stopped by turning the valve a half turn. Thereafter, within a fraction of a second, the electric current through the cell and the pump were switched off. After the solution in the tube between the valve and the overflow-vessel were free from rising bubbles, a gas burette was placed onto the inlet of the overflowvessel. The gas inside the inner tube of the valve flowed into the gas burette. The gas burette was thermostatted.

Because of the special construction of the valve, the gas present in the circuit solution below the valve did not flow into the gas burette. 


\subsection{Electrolysis conditions}

The experiments were carried out with average current densities up to $6 \mathrm{kA} \mathrm{m}^{-2}$ using a $22 \mathrm{wt} \% \mathrm{NaOH}$ solution at temperatures between 313 and $343 \mathrm{~K}$, mostly, at $323 \mathrm{~K}$. It has been found that at these temperatures the difference in temperature of the solution between the bottom and the top of the cell is negligible for the applied currents and solution flow rates. The volumetric rate of solution flow was varied between $2 \times 10^{-6}$ and $20 \times 10^{-6} \mathrm{~m}^{3} \mathrm{~s}^{-1}$.

\section{Results}

\subsection{Ohmic resistance of solution}

3.1.1. Introduction. The alternating current impedance technique is widely used to determine the ohmic resistance of the solution of an electrochemical cell. This technique is well described in [7]. The impedance of the top part of the cell consisting of both the top segments and the solution in between was measured, whereas the other segments were connected to the constant voltage source. The direct current, $I_{20}$, for the top part of the cell was varied between 0.020 and $2.5 \mathrm{~A}$. It was found that for the whole current range the $Z^{\prime} \mid Z^{\prime \prime}$ curve intersects the $Z^{\prime}$ axis at a frequency of about $5000 \mathrm{~Hz}$ when the current through the other segments $I_{1-19}$ was practically zero.

The ohmic resistance of the solution between the top segments, $R_{20}$, is equal to the impedance at $Z^{\prime \prime}=0$ in the high-frequency range from 4000 to $6000 \mathrm{~Hz}$. A characteristic result for the dependence of $R_{20}$ on $I_{20}$ when $I_{1-19}$ is practically zero is given in Fig. 1. From this curve it follows that $R_{20}$ increases linearly with increasing $I_{20}$. The intersection of the $R_{20} / I_{20}$ curve with the $R_{20}$ axis gives $R_{\mathrm{p}, 20}$ being $R_{20}$ in the absence of gas evolution.

From Fig. 1 it follows that $R_{\mathrm{p}, 20}=0.186 \Omega$. Using the relation $R_{\mathrm{p}}=\rho_{\mathrm{p}} / A_{\mathrm{e}}$ and introducing $d_{\mathrm{ac}}=$ $3.2 \times 10^{-3} \mathrm{~m}, A_{\mathrm{e}}=2.4 \times 10^{-4} \mathrm{~m}^{2}$ and $\rho_{\mathrm{p}}=1.506 \times$ $10^{-2} \Omega \mathrm{m}$ [8], it was calculated that $R_{\mathrm{p}, 20}=0.201 \Omega$. Taking into account the inaccuracy of the ratio $d_{\mathrm{ac}} / A_{\mathrm{e}}$ it can be concluded that the experimental and calculated $R_{\mathrm{p}, 20}$ agree reasonably.

The current through each pair of segments was regulated by a unit of the constant-voltage source. This unit was used to switch off or on the current through the pair of segments connected to this unit. Unless otherwise stated, the segment pairs 1 to 19 inclusive were charged by the constant-voltage source and the segment pair 20 by the impedance meter.

It was found that the current $I_{1-19}$ affects the minimum $I_{20}$ where reliable results for $R_{20}$ are still obtained. This minimum increases with increasing $I_{1-19}$ and is equal to about $0.3 \mathrm{~A}$ for $I_{1-19}=25 \mathrm{~A}$ and $0.1 \mathrm{~A}$ for $I_{1-19}=3 \mathrm{~A}$. The cell voltage for segment pair 20 during the measurement of impedance indicates the reliability of $R_{20}$. The cell voltage decreases strongly with decreasing $I_{20}$ at high $I_{1-19}$. For instance, for $I_{1-19}=25 \mathrm{~A}$ the cell voltage for segment pair 20

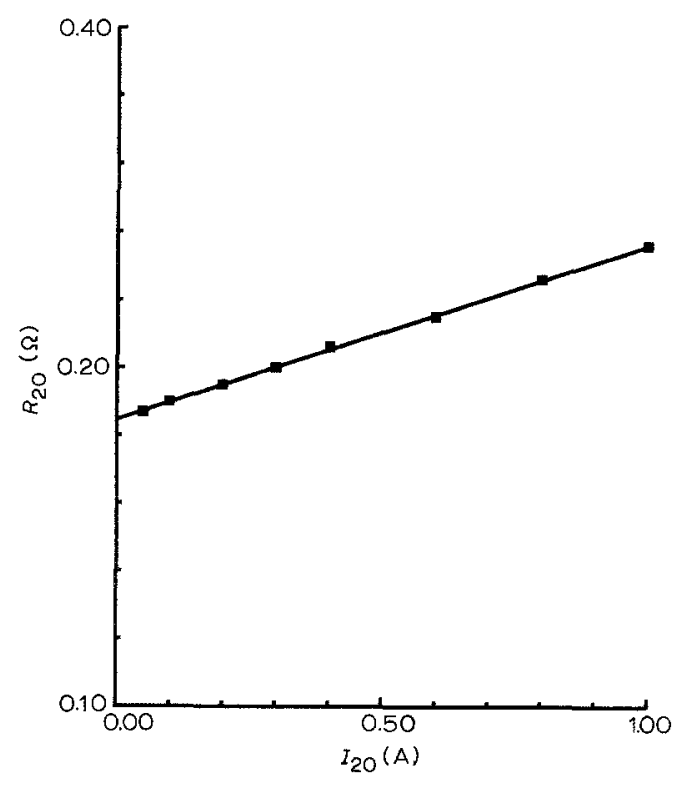

Fig. 1. The ohmic resistance of the solution between the top segments of the segmented anode and cathode, $R_{20}$, as a function of the current through the top segments, $I_{20}$, at $I_{1-19}=0 \mathrm{~A}$ and $Q_{1}=6.0 \times 10^{-6} \mathrm{~m}^{3} \mathrm{~s}^{-1}$.

is $-0.09,1.73,1.98$ and $2.11 \mathrm{~V}$ for, respectively, $I_{20}=0.1,0.2,0.3$ and $0.4 \mathrm{~A}$. From the preceding it follows that reliable results for $R_{20}$ can be obtained for $I_{20}$ above a minimum $I_{20}$ depending on $I_{1-19}$.

3.1.2. Effect of current and volumetric gas flow rate. The ohmic resistance of the solution for segment pair $20, R_{20}$, was determined at various rates of gas evolution on segment pair 20 and on segment pairs located downwards.

In Fig. 2 the reduced resistance $r_{20}$, being $R_{20} / R_{\mathrm{p}, 20}$ is plotted as a function of $I_{1-19}$ for various $I_{20}$. In this case all the segments located downwards were charged with a current $I_{\mathrm{s} \text {,av }}$ being $I_{1-19}$ divided by 19 . Figure 2 shows that the $r_{20} / I_{1-19}$ curves are practically straight and, moreover, almost parallel to one another. The

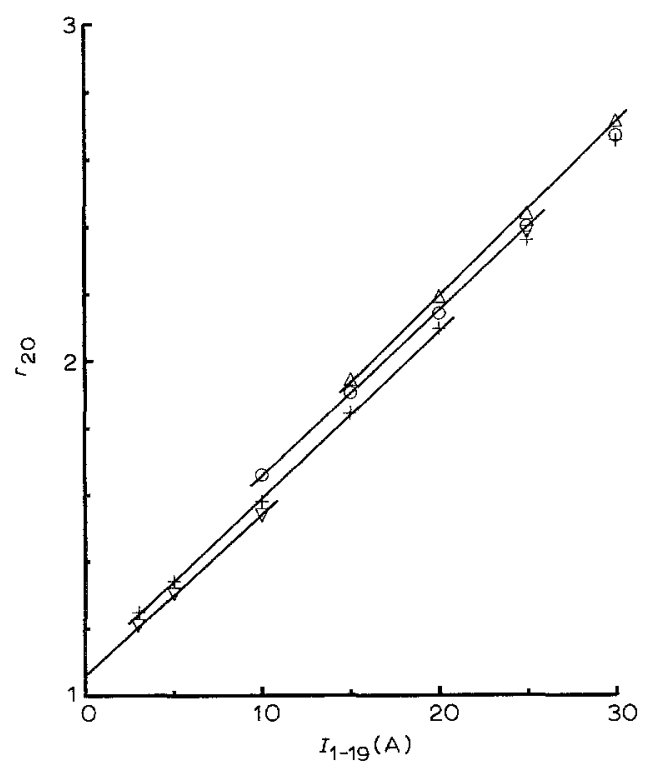

Fig. 2. The reduced ohmic resistance $r_{20}$ as a function of the total current passed through the segment pairs from 1 to 19 inclusive, $I_{1-19}$, at various $I_{20}$ and at $Q_{1}=6.0 \times 10^{-6} \mathrm{~m}^{3} \mathrm{~s}^{-1} \cdot I_{20}:(\Delta) 1 \mathrm{~A}$ (O) $0.8 \mathrm{~A} ;(+) 0.4 \mathrm{~A}$; ( $) 0.2 \mathrm{~A}$ 


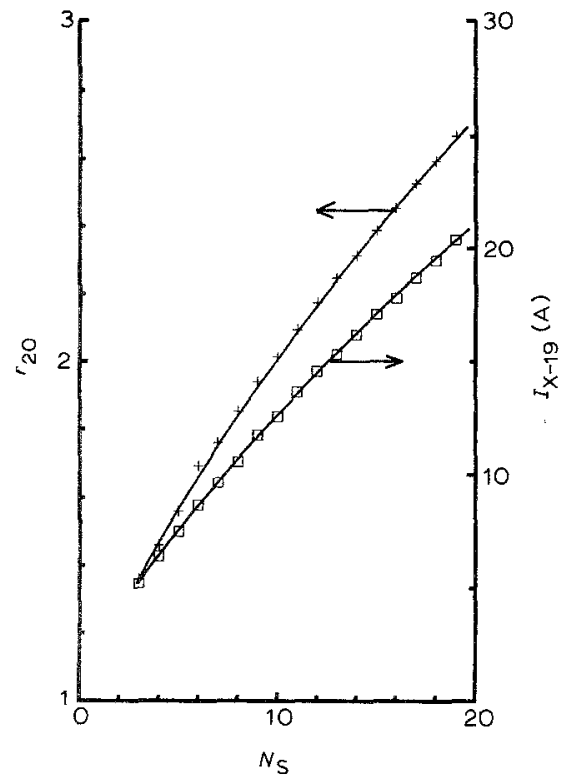

Fig. 3. The reduced ohmic resistance $r_{20}$ at $I_{20}=0.4 \mathrm{~A}$ and the total current passed through the gas-evolving segment pairs, $I_{x-19}$, as a function of the total number of gas-evolving segment pairs where the series of experiments starts with segment pair 19. The volumetric rate of liquid $Q_{1}=6.0 \times 10^{-6} \mathrm{~m}^{3} \mathrm{~s}^{-1}$.

volumetric rate of the gas flow at the level of the lower edge of segment 20, $Q_{\mathrm{g}, 20}$, was also varied by decreasing of the number of current-passing pairs of segments.

At the start of the series of experiments all segments were switched on. The current was switched off for successive segment pairs, starting with the bottomsegment pair. During this series of experiments, the potential difference for the current-passing segment pairs was kept constant. In Fig. $3 I_{x-19}$ and $r_{20}$ at $I_{20}=0.4 \mathrm{~A}$ are plotted against the total number of gas-evolving segment pairs, $N_{\mathrm{s}}$. From this figure it follows that up to about $N_{\mathrm{s}}=10, I_{x-19}$ as well as $r_{20}$ increases linearly with increasing $N_{s}$, and so with increasing height in the cell. Comparing Figs. 2 and 3 it follows that $r_{20}$ at $I_{20}=0.4 \mathrm{~A}$ increases linearly with the total current used for gas evolution on segment pairs located downwards and does not depend on the current distribution over the downwards located segment pairs.

For the series of experiments for which results are given in Fig. 2, the reduced resistance $r_{20}$ is given in Fig. 4 as a function of $I_{20}$. In this $I_{20}$ range $r_{20}$ inclines very sharply with decreasing $I_{20}$. To obtain reliable results the ratio of $I_{20}$ to the current through the segment pairs next to segment pair 20 has to be sufficiently large (see \$3.1). Fig. 4 shows that the slope of the $r_{20} / I_{20}$ curve decreases with increasing $I_{1-19}$. Moreover, the $r_{20} / I_{20}$ line at low $I_{20}$ may be slightly bent for high $I_{1-19}$.

To get insight into the distribution of bubbles between the top segments, gas bubbles were evolved at a group of only 4 successive segment pairs located downwards where the other segments were swtiched off. $r_{20}$ was determined for various distances between the top edge of this group of gas-evolving pairs and the lower edge of the top-segment pair. The measurements were carried out for both decreasing and

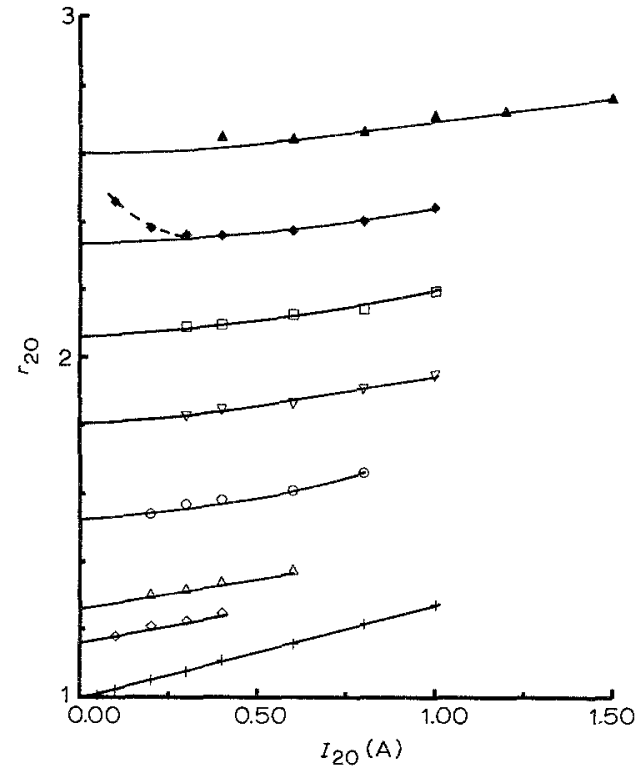

Fig. 4. The reduced ohmic resistance $r_{20}$ as a function of $I_{20}$ for various total current passed through the segment pairs from 1 to 19 inclusive, $I_{1-19}$, and at $Q_{1}=6.0 \times 10^{-6} \mathrm{~m}^{3} \mathrm{~s}^{-1}$. $I_{1-19}:(+) 0 \mathrm{~A}$

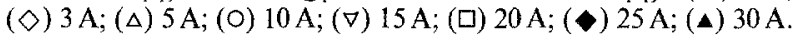

increasing distance between the group of gas-evolving pairs and the top-segment pair. It was found that the reduced resistance $r_{20}$ at $I_{20}=0.4 \mathrm{~A}$ does not depend on the distance between segment pair 20 and the group of gas-evolving pairs on which gas was evolved. From this result it is concluded that the bubbles formed at lower sites are uniformly distributed over the higher cross-section of the cell.

The reduced resistance $r_{20}$ was also determined for three series of experiments with a constant total rate of gas evolution on an increasing number of segment pairs. The total current was adjusted to $2.0,1.5$ and $1.0 \mathrm{~A}$ and the gas-evolving segment pairs were, successively, 19, 18-19, 17-19, 16-19, 15-19 and 14-19. This means that the current density on a gasevolving segment decreased with increasing number of gas-evolving segments. The reduced resistance $R_{20}$ at $I_{20}$ from 0.4 to 0.8 A was practically independent of the number of gas-evolving segment pairs. This result also indicates that the distribution of bubbles formed at lower sites is practically uniform over a cross-section of the cell.

3.1.3. Effect of volumetric liquid flow rate. The effect of the volumetric rate of liquid flow was investigated by performing a series of experiments at various $Q_{1}$. For a series of experiments $r_{20}$ at various $I_{20}$ was determined for decreasing $I_{1-19}$. Figure 5 shows $r_{20}$ at $I_{20}=0.4 \mathrm{~A}$ as a function of the inverse of the volumetric rate of liquid flow, $Q_{1}^{-1}$, at various $I_{1-19}$. Moreover at low $Q_{1}$, viz. $3.0 \times 10^{-6} \mathrm{~m}^{3} \mathrm{~s}^{-1}$ it was found that $r_{20}$ reaches a maximum at $I_{1-19}=20 \mathrm{~A}$ and thereafter $r_{20}$ declines with increasing $I_{1-19}$. The maximum $r_{20}$ is reached at a gas volumetric flow ratio, $\beta$, of about 0.60 . The gas-vapour volumetric flow ratio, $\beta$, is defined as $Q_{\mathrm{g}} /\left(Q_{\mathrm{g}}+Q_{1}\right)$, where $Q_{\mathrm{g}}$ is the volumetric rate of gas saturated with water vapour. From Fig. 5 it follows that for $Q_{1}>6.0 \times 10^{-6} \mathrm{~m} \mathrm{~s}^{-1}, r_{20}$ at 


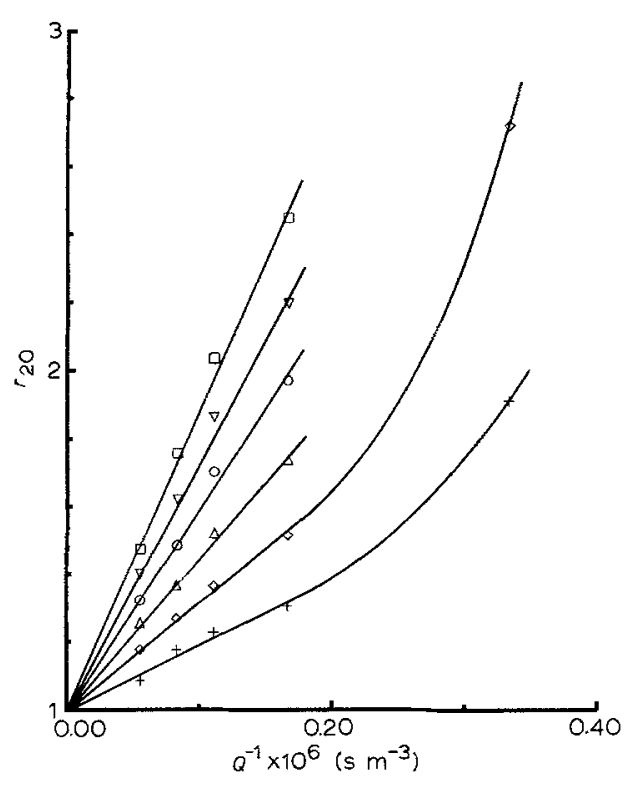

Fig. 5. The reduced ohmic resistance $r_{20}$ at $I_{20}=0.4 \mathrm{~A}$ as a function of the inverse of the volumetric rate of liquid, $Q_{1}^{-1}$, at various $I_{\mathrm{t}-19}$.

$I_{20}=0.4 \mathrm{~A}$ is proportional to $Q_{1}^{-0.50}$. The same proportionality between $r_{20}$ and $Q_{1}$ was also found for the other values of $I_{20}$.

\subsection{Relation between the reduced resistance of solution and void fraction}

Both the reduced resistance of the solution between the top segments at various $I_{20}$ and the void fraction of the solution in the valve between the top of the cell and the overflow-vessel were determined during the same experiment at $I_{1-19}=25 \mathrm{~A}$ and $Q_{1}=18.0 \times 10^{-6} \mathrm{~m}^{3} \mathrm{~s}^{-1}$ corresponding to $v_{1,0}=0.56 \mathrm{~m} \mathrm{~s}^{-1}$. Assuming $100 \%$ current efficiencies for both $\mathrm{H}_{2}$ and $\mathrm{O}_{2}$ evolution, and neglecting the dissolution of both gases it can be calculated that the volumetric rate of formation of gas saturated with water vapour is $5.662 \mathrm{~cm}^{3} \mathrm{~s}^{-1}$ at $323 \mathrm{~K}$ and a pressure of 1 atmosphere. It can be calculated that at $I_{20}=0$ the factor $\beta_{20}=0.239$ at a pressure of 1 atmosphere.

From five measurements it was found that the void fraction of the solution present in the valve would be $\varepsilon_{\mathrm{v}}=0.234 \pm 0.005$ at a pressure of 1 atmosphere.

Using the Bruggeman equation, viz. $r=(1-\varepsilon)^{-3 / 2}$, it can be calculated that $\varepsilon_{20}=0.212 \pm 0.004$ and would be 0.23 at a pressure of 1 atmosphere. The reduced resistance at $I_{20}=0 \mathrm{~A}$ is equal to $1.43 \pm 0.01$. This value was obtained by extrapolation of the $r_{20} / I_{20}$ curve to $I_{20}=0 \mathrm{~A}$ for the experiments with $v_{1,0}=0.56 \mathrm{~m} \mathrm{~s}^{-1}$.

\section{Theory}

To simplify the treatment of the increase in the ohmic resistance of the cell due to the presence of gas bubbles, a half-cell with a rectangular configuration is discussed. Such a simple geometry was also studied by Tobias [9] and Vogt [2].

The half-cell is a rectangular cell compartment of which one wall is formed by a gas-evolving flat-plate electrode and the opposite one by a real or an imaginary flat-plate separator. The following assumptions are made:

- The height $h_{\mathrm{e}}$ and the width $w_{\mathrm{e}}$ of the electrode and the separator are much larger than the distance between electrode and separator.

- The electrode is perfectly electrically conductive; its potential and that of the separator are constant.

- The flow of current in the cell is unidirectional, the current flows only through the electrode and the separator, the other walls of the half-cell are electrically insulated.

- The velocity profile of the liquid in the half-cell corresponds to plug flow, its volumetric flow rate is constant.

- The temperature is constant in the whole half-cell.

- The gas voidage in the bulk of solution at the bottom $(h 0)$ is zero and at the top is $\varepsilon_{t}$.

The most recent model was presented by BongenaarSchlenter [4, 5]. She introduced a bubble layer adjacent to the surface of the gas-evolving electrode. The thickness of the bubble layer at $h=0$ is indicated by $\delta_{0}$ and the voidage at $x=0$ and $h=0$ by $\varepsilon_{0,0}$.

The voidage in the bubble layer at the bottom of the cell $\left(x<\delta_{0}\right)$ is given by

$$
\varepsilon_{x, 0}=\varepsilon_{0,0}-\frac{\varepsilon_{0,0} x}{\delta_{0}}
$$

A bubble-liquid mixture can be considered as a random dispersion of spherical insulators with a large size-range of spheres; the Bruggeman equation is used to calculate its ohmic resistance [10]. The Bruggeman equation is

$$
R=R_{\mathrm{p}}(1-\varepsilon)^{-3 / 2}
$$

where $R$ is this ohmic resistance of the bubblecontaining solution of a voidage, $\varepsilon$, and $R_{\mathrm{p}}$ is the ohmic resistance of the bubble-free solution.

The specific surface resistivity of the bubble-free bulk solution, i.e. between $x=\delta_{0}$ and $x=d_{\mathrm{wm}}$, at the bottom of the cell is given by

$$
\gamma_{\mathrm{s}, 1}=\rho_{\mathrm{p}}\left(d_{\mathrm{wm}}-\delta_{0}\right)
$$

and that of the bubble layer, i.e. between $x=0$ and $x=\delta_{0}$, at the bottom of the cell is given by

$$
\gamma_{\mathrm{s}, 2}=\rho_{\mathrm{p}} \int_{0}^{\delta_{0}}\left(1-\varepsilon_{x, 0}\right)^{-1.5} \mathrm{~d} x
$$

Summing these two specific surface resistivities gives the specific surface resistivity of the solution between the electrode and the separator at $h=0$; so

$$
\gamma_{\mathrm{s}}=\gamma_{\mathrm{s}, 1}+\gamma_{\mathrm{s}, 2}
$$

The resistivity of the bubble-free solution between the working electrode and the separator does not depend on the height in the cell compartment; so the specific surface resistivity is given by

$$
\gamma_{\mathrm{s}, \mathrm{p}}=\rho_{\mathrm{p}} d_{\mathrm{wm}}
$$




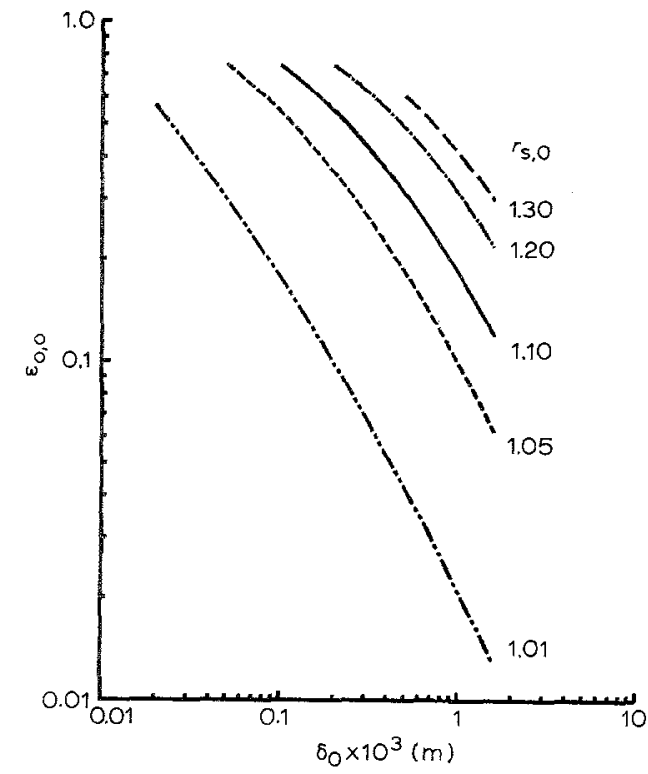

Fig. 6. The voidage at the electrode surface, $\varepsilon_{0,0}$ as a function of thicknesses of Nernst bubble layer for the bottom level in the half-cell where $h=0$ at various reduced specific surface resistance. The distance between the electrode and the separator, $d_{\mathrm{wm}}$, is $1.6 \mathrm{~mm}$.

where $d_{\mathrm{wm}}$ is the distance between the working electrode and the separator.

The reduced specific surface resistivity is defined by $r_{s}=\gamma_{s} / \gamma_{s, p}$. From this definition and Equations 3-6 it follows that the reduced specific surface resistivity at the bottom of the half-cell, i.e. at $h=0$ is given by

$r_{\mathrm{s}, 0}=\frac{1}{d_{\mathrm{wm}}} \int_{0}^{\delta_{0}}\left(1-\varepsilon_{x, 0}\right)^{-1.5} \mathrm{~d} x+\left(\frac{d_{\mathrm{wm}}-\delta_{0}}{d_{\mathrm{wm}}}\right)$

where $\varepsilon_{x, 0}$ is given by Equation 1. $r_{s, 0}$ was numerically calculated for various $\delta_{0}, \varepsilon_{0,0}$ and $d_{\mathrm{wm}}$. Figure 6 shows $\varepsilon_{0,0} / \delta_{0}$ curves at various $r_{\mathrm{s}, 0}$.

The effect of the void fraction in the bulk of solution on the void fraction at the electrode surface has not yet been discussed in the literature. Moreover, at a constant volumetric flow rate of liquid the void fraction in the bulk of solution also affects the liquid velocity.

To elucidate the effect of void fraction in the bulk solution, the specific surface resistivity of the solution between the gas-evolving electrode and the imaginary separator was calculated for different models describing the effect of the voidage in the bulk of solution on the thickness of bubble layer and the voidage at the gas-evolving electrode [11].

These models can be replaced by a general model where the voidage in the bubble layer with a thickness $\delta_{0}$, that is at $0<x<\delta_{0}$, is given by

$$
\varepsilon_{x, h}^{n_{1}}=\varepsilon_{0,0}^{n_{1}}\left(1-\frac{x}{\delta_{0}}\right)^{n_{1}}+\varepsilon_{\infty, h}^{n_{1}}
$$

and the voidage in the bulk solution layer, that is at $\delta_{0}<x<d_{\mathrm{wm}}$, is given by

$$
\varepsilon_{x, h}=\varepsilon_{\infty, h}
$$

It can be shown that the reduced specific surface

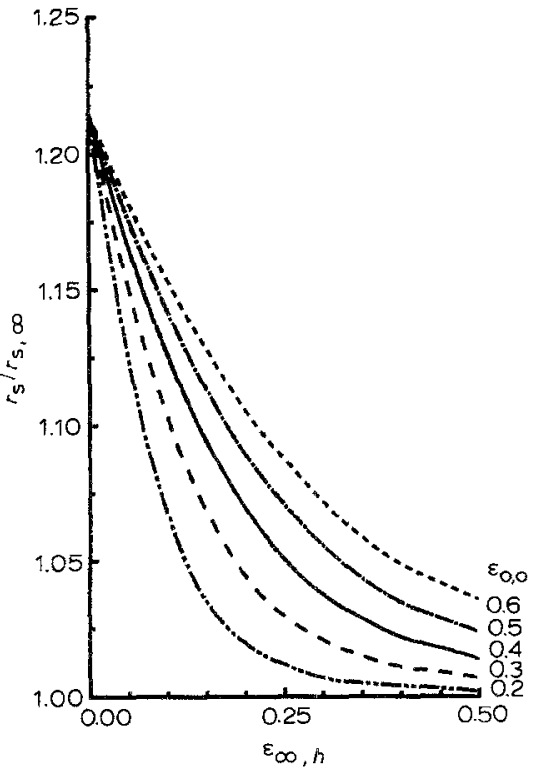

Fig. 7. $r / r_{\mathrm{s}, \infty}$ is plotted versus $\varepsilon_{\infty, h}$ for $r_{\mathrm{s}, 0}=1.215, d_{\mathrm{wm}}=1.6 \mathrm{~mm}$, $n_{1}=4$ and various $\varepsilon_{0,0}$.

resistivity at various $\varepsilon_{\infty, h}$ is given by

$$
\begin{aligned}
r_{\mathrm{s}}= & \frac{1}{d_{\mathrm{wm}}} \int_{0}^{\delta_{0}}\left(1-\varepsilon_{x, h}\right)^{-1.5} \mathrm{~d} x \\
& +\left(1-\varepsilon_{\infty, h}\right)^{-1.5} \frac{\left(d_{\mathrm{wm}}-\delta_{0}\right)}{d_{\mathrm{wm}}}
\end{aligned}
$$

where $\varepsilon_{x, h}$ is given by Equation 8 .

Czarnetzki [11] has calculated the reduced specific surface resistivity for various models as a function of $\varepsilon_{0,0}$ and $\varepsilon_{\infty, h}$. The model where the void fraction at the gas-evolving electrode is independent of the void fraction in the bulk of solution is practically equal to the general model with $n_{1} \rightarrow \infty$. It has been found that for this model the $r_{\mathrm{s}} / \epsilon_{\infty, h}$ curves at various $\varepsilon_{0,0}$ converge with increasing $\varepsilon_{\infty, h}$. For the general model with $n_{1}=1$ the $r_{\mathrm{s}} / \varepsilon_{\infty, h}$ curves at various $\varepsilon_{0,0}$ diverge clearly with increasing $\varepsilon_{\infty, h}[11]$, for the one with $n_{1}=2$ the curves are practically parallel to one

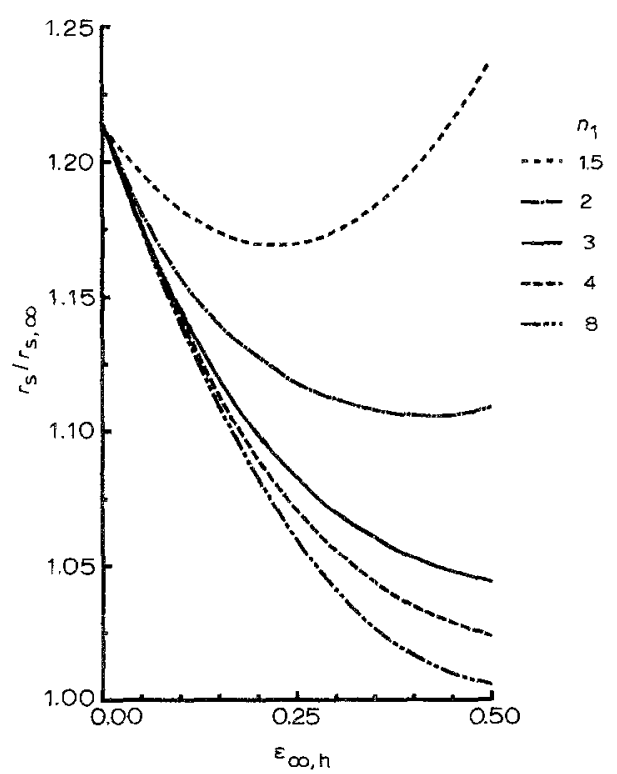

Fig. 8. $r / r_{\mathrm{s}, \infty}$ is plotted against $\varepsilon_{\infty, h}$ for $r_{\mathrm{s}, 0}=1.215, \varepsilon_{0,0}=0.5$ $d_{\mathrm{wm}}=1.6 \mathrm{~mm}$ and various $n_{1}$. 
another [11] and for the one with $n_{1}=3$ the curves converge slightly (unpublished work).

To demonstrate more clearly the most useful model, for various models $r_{\mathrm{s}} / r_{\mathrm{s}, \infty}$ has been calculated as a function of $\varepsilon_{\infty, h}$ at $d_{\mathrm{wm}}=1.6 \mathrm{~mm}$, and at various combinations of $\delta_{0}$ and $\varepsilon_{0,0}$ where $0.1 \mathrm{~mm}<\delta_{0}<1.6 \mathrm{~mm}$. For $n_{1}=4 r_{\mathrm{s}} / r_{\mathrm{s}, \infty}$ is plotted versus $\varepsilon_{\infty, h}$ in Fig. 7 for $r_{\mathrm{s}, 0}=1.215, d_{\mathrm{wm}}=1.6 \mathrm{~mm}$ and various $\varepsilon_{0,0}$. The parameter $\delta_{0}$ has been calculated using Equation 7 . From Fig. 7 it follows that the decrease in $r_{\mathrm{s}} / r_{\mathrm{s}, \infty}$ with increasing $\varepsilon_{\infty, h}$ depends strongly on $\varepsilon_{0,0}$.

The effect of $n_{1}$ on the relation between $r_{\mathrm{s}} / r_{\mathrm{s}, \infty}$ and $\varepsilon_{\infty, h}$ is shown in Fig. 8 for $r_{\mathrm{s}, 0}=1.215$ and $\varepsilon_{0,0}=0.5$. From this figure it follows that the decline in $r_{s} / r_{\mathrm{s}, \infty}$ with increasing $\varepsilon_{\infty, h}$ is more sharp with increasing $n_{1}$.

\section{Discussion}

\subsection{Horizontal distribution of void fraction}

During the electrolysis of a $\mathrm{NaOH}$ solution hydrogen and oxygen bubbles are formed at, respectively, the nickel cathode and anode. The void fraction decreases with increasing distance from the gas-evolving electrode. Bongenaar-Schlenter $[4,5]$ introduced the concept of a bubble layer adjacent to the gas-evolving electrode. The thickness of this first-bubble layer, $\delta$, depends on various parameters.

For a first approach it is reasonable to propose that the differences in $\varepsilon_{0,0}$ and $\delta_{0}$ for the oxygen- and the hydrogen-evolving electrode are neglected. This means that the undivided water electrolyzer with an interelectrode gap of $3.2 \mathrm{~mm}$ is considered as two half-cells with the distance between an electrode and an imaginary separator being $1.6 \mathrm{~mm}$. Based on the experimental results with transparent nickel electrodes at low void fractions in the bulk of solution [12] and assuming the degree of screening of the electrode by bubbles is equal to the void fraction in the solution at the electrode surface, it can be concluded that the void fraction $\varepsilon_{0,0}$ at the leading edge of both the hydrogenand oxygen-evolving nickel electrode in $22 \mathrm{wt} \%$ $\mathrm{NaOH}$ at $323 \mathrm{~K}, 2 \mathrm{kA} \mathrm{m}^{-2}$ and $v_{1,0}=0.2 \mathrm{~m} \mathrm{~s}^{-1}$ is equal to about 0.3 .

The reduced resistance for segment pair 20 in the absence of gas evolution on the other segments can be obtained from Fig. 1 and is equal to 1.103 at $i=2 \mathrm{kA} \mathrm{m}^{-2}$. If the effect of the small height of segment pair $20, v i z .24 \mathrm{~mm}$, on the reduced specific surface resistivity $r_{\mathrm{s}}$ is neglected, then $r_{20}$ at $I_{1-19}=0 \mathrm{~A}$ is $r_{\mathrm{s}, 0}$. Using Equation 7 for $r_{\mathrm{s}, 0}$ and Equation 1 for $\varepsilon_{x, 0}$ it can be calculated that $\delta_{0}=0.55 \mathrm{~mm}$ at $\varepsilon_{0,0}=0.3$.

Bongenaar-Schlenter [4] has determined the thickness of the bubble layer at a hydrogen-evolving electrode in $1 \mathrm{M} \mathrm{KOH}$ at $303 \mathrm{~K}$ and various current densities, liquid-flow rates and distances from the leading edge of the electrode. Using her experimental correlation it has been found that $\delta_{0}=0.22 \mathrm{~mm}$ at $2 \mathrm{kA} \mathrm{m}^{-2}, v_{1,0}=0.188 \mathrm{~m} \mathrm{~s}^{-1}$ and at a distance of $12 \mathrm{~mm}$ from the leading edge of the electrode. The two values for $\delta_{0}$ are of the same order of magnitude.

\subsection{Vertical distribution of void fraction}

From the impedance measurements it follows that the distribution of bubbles formed at the lower parts of the electrode is practically uniform over the bulk of solution (\$3.1.2). The bubbles evolved on the electrode at a cross-section of the cell join the bubbles formed at lower cross-sections of the cell. The compartment between anode and cathode is divided into two equal anodic and cathodic bubble layers and a layer of bulk solution.

From resistance measurements, and using the Bruggeman equation, it has been found that, in the absence of gas evolution on the top segments, the void fraction in the solution between the top segments agrees reasonably with the void fraction in the valve and with the factor $\beta_{20}$ at $I_{20}=0 \mathrm{~A}$ and a pressure of 1 atmosphere. This factor is equal to the void fraction when the bubble-slip ratio $S_{\mathrm{b}}=1$ and the supersaturation of solution by the gases formed is negligible (\$3.3). The experiments of (\$3.3) were carried out at a relatively high solution velocity, namely $v_{1,0}=0.56 \mathrm{~m} \mathrm{~s}^{-1}$.

The natural rise velocity of a single electrolysis bubble is in the order of $0.002 \mathrm{~m} \mathrm{~s}^{-1}$ [13]. Consequently, the effect of bubble slip at $v_{1,0}=0.56 \mathrm{~m} \mathrm{~s}^{-1}$ can be neglected. Moreover, from the preceding discussion it follows that between the top segments and under the conditions of the experiments of (\$3.3) the supersaturation of solution can be neglected.

Figure 4 shows $r_{20} / I_{20}$ curves at various $I_{1-19}$ for a relatively low liquid flow rate, namely $v_{1,0}=0.188 \mathrm{~m} \mathrm{~s}^{-1}$. Extrapolation of the $r_{20} / I_{20}$ curve gives $r_{20}$ at $I_{20}=0 \mathrm{~A}$. This parameter is plotted against $I_{1-19}$ in Fig. 9. Using the Bruggeman relation the void fraction $\varepsilon_{\infty, 20}$ has been calculated. This void fraction has been plotted as a function of $I_{1-19}$ in Fig. 9. The gas volumetric flow ratio, $\beta_{20}$, in the cell at the leading edge of the top segment pair has been calculated and is also plotted in Fig. 9, where it has been taken into account that the pressure is about $8 \%$ higher than the atmospheric pressure and the gas evolved is saturated with water vapour.

From Fig. 9 it follows that the resistivity $r_{20}$ at $I_{20}=0 \mathrm{~A}$ increases linearly with increasing $I_{1-19}$ and that the void fraction $\varepsilon_{\infty, 20}$ at $I_{20}=0$ is clearly smaller than the gas volumetric flow ratio $\beta_{20}$. Since the supersaturation of the solution between the top segments is negligible, the difference between $\varepsilon_{\infty, 20}$ and $\beta_{20}$ is caused by a higher bubble velocity than the linear velocity of liquid.

From the relations for the bubble-slip ratio, viz. $S_{\mathrm{b}}=v_{\mathrm{g}} / v_{\mathrm{l}}$, the void fraction $\varepsilon$ and the gas volumetric flow ratio $\beta$ [14] it can be deduced that

$$
S_{\mathrm{b}}=\frac{Q_{\mathrm{g}}^{(1-\varepsilon)}}{Q_{1} \varepsilon}
$$

The calculated bubble-slip ratio at the top segments in the absence of gas evolution on the top segments, $S_{\mathrm{b}, 20}$ is also plotted against $I_{1-19}$ in Fig. 9. From this figure it can be deduced that $S_{\mathrm{b}, 20}$ increases practically linearly 


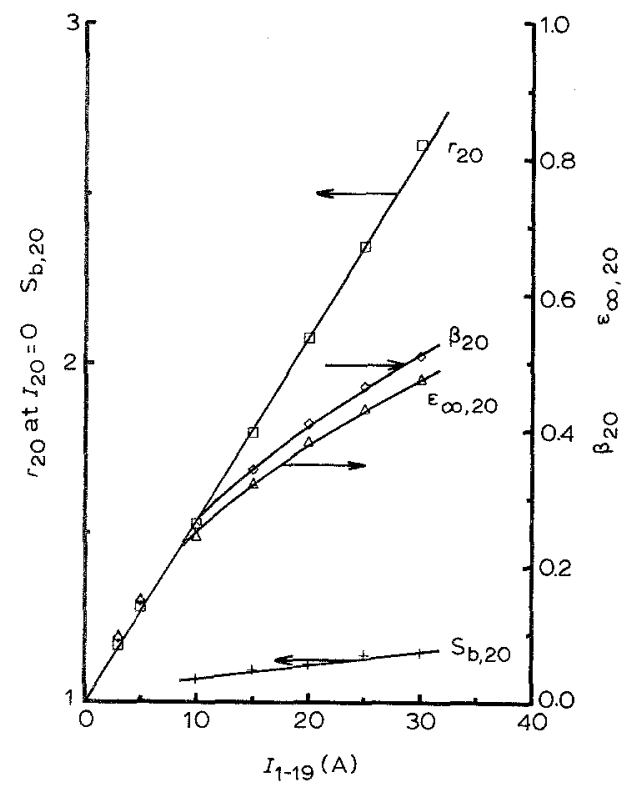

Fig. 9. $r_{20}$ at $I_{20}=0 \mathrm{~A}, \varepsilon_{\infty}, 20, \beta_{20}$ and $S_{\mathrm{b}, 20}$ are plotted against $I_{1-19}$ for a hydrogen and oxygen-evolving cell in $22 \mathrm{wt} \% \mathrm{NaOH}$ at $323 \mathrm{~K}$ and a volumetric rate of liquid flow of $6.0 \times 10^{-6} \mathrm{~m}^{3} \mathrm{~s}^{-1}$.

with increasing $\beta_{20}$ and increases exponentially with increasing void fraction.

Consequently,

$$
S_{\mathrm{b}, h}=b_{\mathrm{s}}+a_{\mathrm{s}} \beta_{h}
$$

where $b_{\mathrm{s}}$ is the intersection on the $S_{\mathrm{b}}$ axis and $a_{\mathrm{s}}$ is the slope of the $S_{\mathrm{b}, 20} / \beta_{20}$ straight line. The factors $a_{\mathrm{s}}$ and $b_{\mathrm{s}}$ depend on $v_{1,0}$.

Assuming the current distribution over the cathode is the same as that over the anode, the volumetric rate of the gas flow at a height $h$ in the cell is given by

$$
Q_{\mathrm{g}, h}=\frac{\int_{0}^{h} V_{\mathrm{m}} i w_{\mathrm{e}} \mathrm{d} h}{\left(n_{\mathrm{a}}+n_{\mathrm{c}}\right) F}
$$

where $V_{\mathrm{m}}$ is the volume of $1 \mathrm{~mol}$ gas saturated with water vapour, $n_{\mathrm{a}}$ is the number of electrons involved in the anodic reaction, and $n_{\mathrm{c}}$ is the number of electrons involved in the cathodic reaction.

The voidage in the bulk of solution at a height $h$ in the cell, $\varepsilon_{\infty, h}$, can be obtained from Equations 11, 12 and 13 .

\subsection{Effect of the bulk of solution voidage on the voidage at the gas-evolving electrode}

Figure 2 shows that $r_{20} / I_{1-19}$ curves at various $I_{20}$ are practically parallel to one another or converge slightly. Using the Bruggeman relation it can be shown that $r_{20}$ at $I_{20}=0 \mathrm{~A}$ is $\left(1-\varepsilon_{\infty, 20}\right)^{-1.5}$ where $\varepsilon_{\infty, 20}$ is the voidage in the bulk solution at $I_{20}=0 \mathrm{~A}$ and at the level of segment pair 20. It can be shown that $r_{20}$ corresponds to $r_{\mathrm{s}, 20}$ and $r_{20}$ at $I_{20}=0 \mathrm{~A}$ to $r_{\mathrm{s}, \infty, 20}$.

From numerical calculations it follows that the shape of the $r_{\mathrm{s}} / r_{\mathrm{s}, \infty}$ against $\varepsilon_{\infty}$ curve depends strongly on $n_{1}, \varepsilon_{0,0}$ and $\delta_{0}$. Only for $n_{1}=1$ the curves at every $\varepsilon_{0,0}$ and $\delta_{0}$ diverge. Comparing the experimental $r_{20} / I_{1-19}$ curves with the theoretical $r_{\mathrm{s}} / \varepsilon_{\infty}$ curves it follows that $n_{1}>1$.

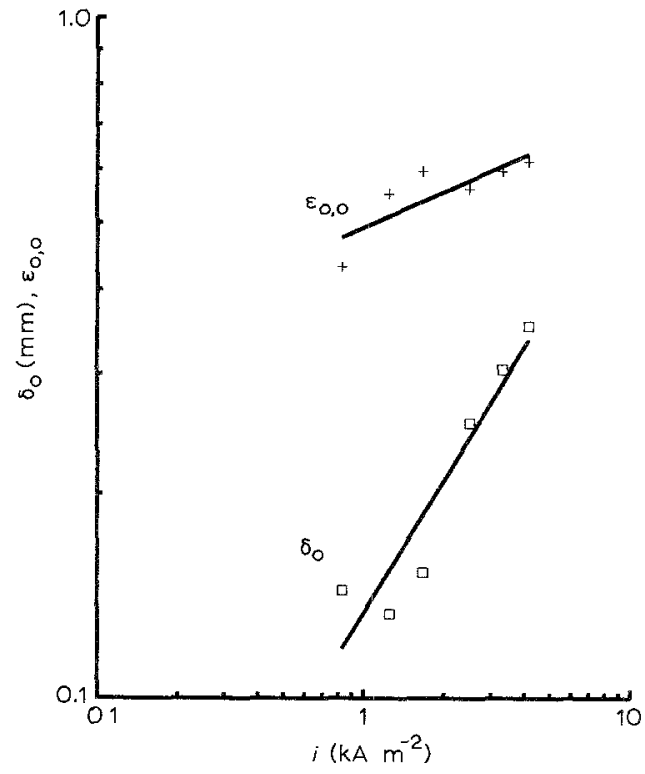

Fig. 10. $\varepsilon_{0,0}$ and $\delta_{0}$ are plotted as a function of current density on a double logarithmic scale for a hydrogen and oxygen-evolving cell in $22 \mathrm{wt} \% \mathrm{NaOH}$ at $323 \mathrm{~K}$ and a velocity of liquid flow of $1.88 \times 10^{-2} \mathrm{~m} \mathrm{~s}^{-1}$

To determine $n_{1}$, experimental data from Fig. 4 are used, viz.

$-r_{\mathrm{s}, 0}=1+0.515 \times 10^{-4} i$, where $i$ is given in $\mathrm{A} \mathrm{m}^{-2}$ and $r_{\mathrm{s}, 0}=r_{20}$ at $I_{1-19}=0 \mathrm{~A}$,

$-r_{\mathrm{s}, 20}$ at various $I_{1-19}$ and $I_{20}=0 \mathrm{~A}$ where $r_{\mathrm{s}, 20}=$ $r_{20}$ at $I_{20}=0 \mathrm{~A}$ obtained by extrapolation,

- $r_{\mathrm{s}, 20}$ at various $I_{20}$ and $I_{1-19}$ where $r_{\mathrm{s}, 20}$ is more than about $2 \%$ higher than $r_{\mathrm{s}, 20}$ at $I_{20}=0 \mathrm{~A}$. This limitation has been chosen to eliminate the most inaccurate results.

It was found that for $n_{1}<2.5$, the calculated $\varepsilon_{0,0}$ increases up to a fixed $I_{20}$ and thereafter decreases with increasing $I_{20}$. This result contradicts the generally accepted experimental result, viz. $\varepsilon_{0,0}$ increases continuously with increasing current density $[3,5,12]$. Moreover, for $n_{1}<2.5$ the calculated $\varepsilon_{0,0}$ decreases with increasing $I_{1-19}$ or $\varepsilon_{\infty, h}$. This is also an unrealistic result. Consequently, $n_{1}$ has to be higher than 2.5 .

It was found that the best fit for the experimental results given in Fig. 4 was obtained for $n_{1}=4$. Consequently, the effect of the voidage in the bulk of solution on that within the bubble layer with a thickness $\delta_{0}$ at the electrode surface is given by

$$
\varepsilon_{x, h}^{4}=\varepsilon_{0,0}^{4}\left(1-\frac{x}{\delta_{0}}\right)^{4}+\varepsilon_{\infty, h}^{4}
$$

From Equation 14 it follows that the voidage profile in the layer with thickness $\delta_{0}$ changes with increasing $\varepsilon_{\infty, h}$. Since $\varepsilon_{\infty, h}$ increases with increasing height $h$ the voidage profile in the layer with thickness $\delta_{0}$ also changes with increasing height.

The calculated values of $\varepsilon_{0,0}$ and $\delta_{0}$ are plotted in Fig. 10 as a function of current density, $i$, for the experiments of Fig. 4.

The calculated results for $\varepsilon_{0,0}$ as well as for $\delta_{0}$ agree reasonably with the experimental results $[3,4]$, where it has to be taken into account that to calculate $\varepsilon_{0,0}$ and 
$\delta_{0}$ the oxygen- and hydrogen-evolving cell is considered as two identical gas-evolving half-cells.

\section{References}

[1] H. Vogt, in 'Comprehensive Treatise of Electrochemistry', Vol. 6 (edited by E. Yeager, J. O'M. Bockris, B. E. Conway and S. Sarangapani), Plenum Press, New York (1983) p. 476.

[2] H. Vogt, Electrochim. Acta 26 (1981) 1311.

[3] C. W. M. P. Sillen, $\mathrm{PhD}$ thesis, Eindhoven University of Technology, Eindhoven (1983)

[4] B. E. Bongenaar-Schlenter, PhD thesis, Eindhoven University of Technology, Eindhoven (1984).

[5] B. E. Bongenaar-Schlenter, L. J. J. Janssen, S. J. D. van Stralen and E. Barendrecht, J. Appl. Electrochem. 15 (1985) 537.
[6] L. R. Czarnetzki and L. J. J. Janssen, ibid. 19 (1989) 630.

[7] R. Greef, R. Peat, L. M. Peter, D. Pletcher and J. Robinson, 'Instrumental Methods in Electrochemistry', Ellis Horwood. Chichester (1986).

[8] E. W. Washburn, 'International Critical Tables', Vol. VI McGraw-Hill, New York (1929) 254.

[9] C. W. Tobias, J. Electrochem. Soc. 106 (1959) 833.

[10] R. E. De La Rue and C. W. Tobias, J. Electrochem. Soc. 106 (1959) 827.

[11] L. R. Czarnetzki, PhD thesis, Eindhoven University of Technology, Eindhoven (1989).

[12] L. J. J. Janssen, C. W. M. P. Sillen, E. Barendrecht and S. J. D. van Stralen, Electrochim. Acta 29 (1984) 633.

[13] L. J. J. Janssen and J. G. Hoogland, ibid. 15 (1970) 1013.

[14] L. S. Tong, Boiling Heat Transfer and Two-phase Flow, John Wiley \& Sons, New York (1965) p. 47. 